\title{
ORIGINAL
}

\section{Feasibility and safety of ultra-low tidal volume ventilation without extracorporeal circulation in moderately severe and severe ARDS patients}

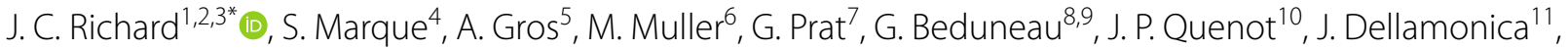

R. Tapponnier ${ }^{12}$, E. Soum ${ }^{13}$, L. Bitker ${ }^{1,2,3}$, J. Richecoeur ${ }^{14}$ and the REVA research network

@ 2019 Springer-Verlag GmbH Germany, part of Springer Nature

\begin{abstract}
Purpose: Mechanical ventilation with ultra-low tidal volume (VT) during ARDS may reduce alveolar strain, driving pressure and hence ventilator-induced lung injury, with the main drawback of worsening respiratory acidosis. We hypothesized that VT could be reduced down to $4 \mathrm{ml} / \mathrm{kg}$, with clinically significant decrease in driving pressure, without the need for extracorporeal $\mathrm{CO}_{2}$ removal, while maintaining $\mathrm{pH}>7.20$.

Methods: We conducted a non-experimental before-and-after multicenter study on 35 ARDS patients with PaO $/$ $\mathrm{FiO}_{2} \leq 150 \mathrm{mmHg}$, within $24 \mathrm{~h}$ of ARDS diagnosis. After inclusion, VT was reduced to $4 \mathrm{ml} / \mathrm{kg}$ and further adjusted to maintain $\mathrm{pH} \geq 7.20$, respiratory rate was increased up to $40 \mathrm{~min}^{-1}$ and $\mathrm{PEEP}$ was set using a PEEP-FiO $\mathrm{F}_{2}$ table. The primary judgment criterion was driving pressure on day 2 of the study, as compared to inclusion.

Results: From inclusion to day 2, driving pressure decreased significantly from 12 [9-15] to 8 [6-11] $\mathrm{cmH}_{2} \mathrm{O}$, while VT decreased from 6.0 [5.9-6.1] to 4.1 [4.0-4.7] ml/kg. On day 2, VT was below $4.2 \mathrm{ml} / \mathrm{kg}$ in 65\% [Cl $95 \%$ 48\%-79\%], and below $5.25 \mathrm{ml} / \mathrm{kg}$ in $88 \%$ [Cl $\mathrm{Cl}_{95}$ 74\%-95\%] of the patients. 2 patients (6\%) developed acute cor pulmonale after inclusion. Eleven patients (32\%) developed transient severe acidosis with $\mathrm{pH}<7.15$. Fourteen patients (41\%) died before day 90 .

Conclusion: Ultra-low tidal volume ventilation may be applied in approximately $2 / 3$ of moderately severe-to-severe ARDS patients, with a $4 \mathrm{cmH}_{2} \mathrm{O}$ median reduction in driving pressure, at the price of transient episodes of severe acidosis in approximately $1 / 3$ of the patients.
\end{abstract}

Keywords: Acute respiratory distress syndrome, Permissive hypercapnia, ECMO, ECCO2R, ultraprotective ventilation, Driving pressure

\footnotetext{
*Correspondence: j-christophe.richard@chu-lyon.fr

1 Service de Médecine Intensive Réanimation, Hôpital De La Croix Rousse,

Hospices Civils de Lyon, 103 Grande Rue de la Croix Rousse, 69004 Lyon,

France

Full author information is available at the end of the article
} 


\section{Introduction}

Despite improvement in acute respiratory distress syndrome (ARDS) management by using protective ventilation (i.e., tidal volume (VT) $6 \mathrm{ml} . \mathrm{kg}^{-1}$ of predicted body weight $(\mathrm{PBW})$ and plateau pressure $\left(\mathrm{P}_{\mathrm{Plat}}\right)$ below $30 \mathrm{cmH}_{2} \mathrm{O}$ ) and use of prone positioning, ARDS mortality remains high in observational studies [1], and recent randomized controlled trials (RCTs) [2-4]. Clinical data strongly suggests that harmful mechanical ventilation (MV) settings might partly explain the current mortality of ARDS. Indeed, 30\% of ARDS patients under protective ventilation exhibit tidal hyperinflation on computed tomography, associated with an increase in pro-inflammatory mediators in broncho-alveolar lavage (BAL) [5], suggesting excessive VT. Increased driving pressure $(\Delta P$, i.e., the ratio of VT over respiratory system compliance) is independently associated with higher mortality [6-8], and may reflect that a given $\mathrm{VT}$ is too high relative to the end-expiratory lung volume. In a recent observational study [9], an increase of $1 \mathrm{ml} . \mathrm{kg}^{-1}$ in initial VT was associated with a $23 \%$ increase in mortality, suggesting that small VT variations at the initial phase of ARDS may impact prognosis. Reducing VT from 6 to 3-4 ml. $\mathrm{kg}^{-1}$ [ultra-low tidal volume ventilation (ULTV)] combined with extracorporeal $\mathrm{CO}_{2}$ removal (ECCO2R) is associated with a decrease in pro-inflammatory mediators in BAL [10], and lower ventilator-free days (VFD) in the most hypoxemic ARDS patients [11]. However, ECCO2R has, to date, not shown any beneficial effect on ARDS survival, is associated with a high rate of treatment-related adverse events [12], and may increase the burden of healthcare-related costs. As tolerating mild level of hypercapnia is the standard of care in ARDS [13], and since the lowest tolerable $\mathrm{pH}$ without adjustment of MV tend to decrease in recent RCTs $[2,14]$, we hypothesized that the VT could be reduced down to $4 \mathrm{ml} . \mathrm{kg}^{-1}$, with clinically significant decrease in $\Delta P$ and without the need for ECCO2R, while maintaining the $\mathrm{pH}$ in the range targeted in recent RCTs.

\section{Materials and methods Study design}

This trial is a non-experimental before-and-after multicenter study, performed at 11 intensive care units (ICU). The trial was registered at ClinicalTrials.gov (NCT02816372) and the protocol was approved by an ethics committee (RCB 2016-A00503-48). Patients were enrolled between October 2016 and March 2018.

\section{Take-home message}

Ultra-low tidal volume ventilation without extracorporeal circulation is feasible in approximately $2 / 3$ of moderately severe-to-severe ARDS patients. It is associated with a $4 \mathrm{cmH}_{2} \mathrm{O}$ median reduction in driving pressure, at the price of transient episodes of severe acidosis in approximately $1 / 3$ of the patients.

\section{Patients}

Eligible participants were aged 18 years or older, under invasive MV, with ARDS according to the Berlin definition [15], and $\mathrm{a} \mathrm{PaO}_{2} / \mathrm{FiO}_{2} \leq 150 \mathrm{mmHg}$.

Exclusion criteria were ARDS onset $>24 \mathrm{~h}$, planned duration of invasive $\mathrm{MV}<48 \mathrm{~h}$, intracranial hypertension, chronic obstructive pulmonary disease, chronic respiratory failure under home oxygen or non-invasive ventilation, pneumothorax or air leak, morbid obesity (body weight $>1 \mathrm{~kg} . \mathrm{cm}^{-1}$ body height), sickle cell disease, recent bone marrow transplantation, chemotherapyinduced neutropenia, burn injury on more than $30 \%$ of the body surface, hepatic cirrhosis with Child-Pugh score $\mathrm{C}$, treatment by extracorporeal membrane oxygenation or ECCO2R, pregnancy, advance directives to withhold or withdraw life-sustaining treatment, previous inclusion in present study, inclusion in another MV trial during the same ICU stay, patient under a legal protective measure, lack of affiliation to social security, lack of informed consent by patient's relative.

\section{Protocol description}

After inclusion $\left(H_{0}\right.$, day 1$)$, MV was performed in volumeassist control mode with VT lowered by $1 \mathrm{ml} . \mathrm{kg}^{-1} \mathrm{PBW}$ steps down to $4 \mathrm{ml} . \mathrm{kg}^{-1} \mathrm{PBW}$ and further refined using a dedicated algorithm (Table 1), aiming to achieve the following goals: $P_{\text {Plat }} \leq 30 \mathrm{cmH}_{2} \mathrm{O}, 55 \leq \mathrm{PaO}_{2} \leq 80 \mathrm{mmHg}$ (or $88 \% \leq \mathrm{SpO}_{2} \leq 95 \%$ ), and $7.20 \leq \mathrm{pH} \leq 7.45$. ARDS adjunctive therapies were protocolized as follows: administration of neuromuscular blocking agent (NMBA) during $48 \mathrm{~h}$ [14], and daily prone positioning during at least $16 \mathrm{~h}$ if $\mathrm{PaO}_{2} / \mathrm{FiO}_{2}<150 \mathrm{mmHg}$, until achievement of a $\mathrm{PaO}_{2} / \mathrm{FiO}_{2} \geq 150 \mathrm{mmHg}$ with a PEEP $\leq 10 \mathrm{cmH}_{2} \mathrm{O}$ and a $\mathrm{FiO}_{2} \leq 60 \%$ in the supine position [2].

From day 3, a PEEP weaning trial (Online Resource 1) was performed daily if $\mathrm{PaO}_{2} / \mathrm{FiO}_{2}$ was $>150 \mathrm{mmHg}$ in the supine position. After successful completion of this trial, ventilation was performed in volume-assist control mode with VT $6 \mathrm{ml} . \mathrm{kg}^{-1}$ PBW or pressure support targeting VT between 6 and $8 \mathrm{ml} . \mathrm{kg}^{-1} \mathrm{PBW}$, and weaning criteria were screened daily to perform a spontaneous breathing trial (Online Resource 2).

Sedation was adjusted using Richmond AgitationSedation Scale (RASS) score [16], as follows: -5 during NMBA administration, -5 to -4 during prone 
Table 1 Summary of the ventilation procedure

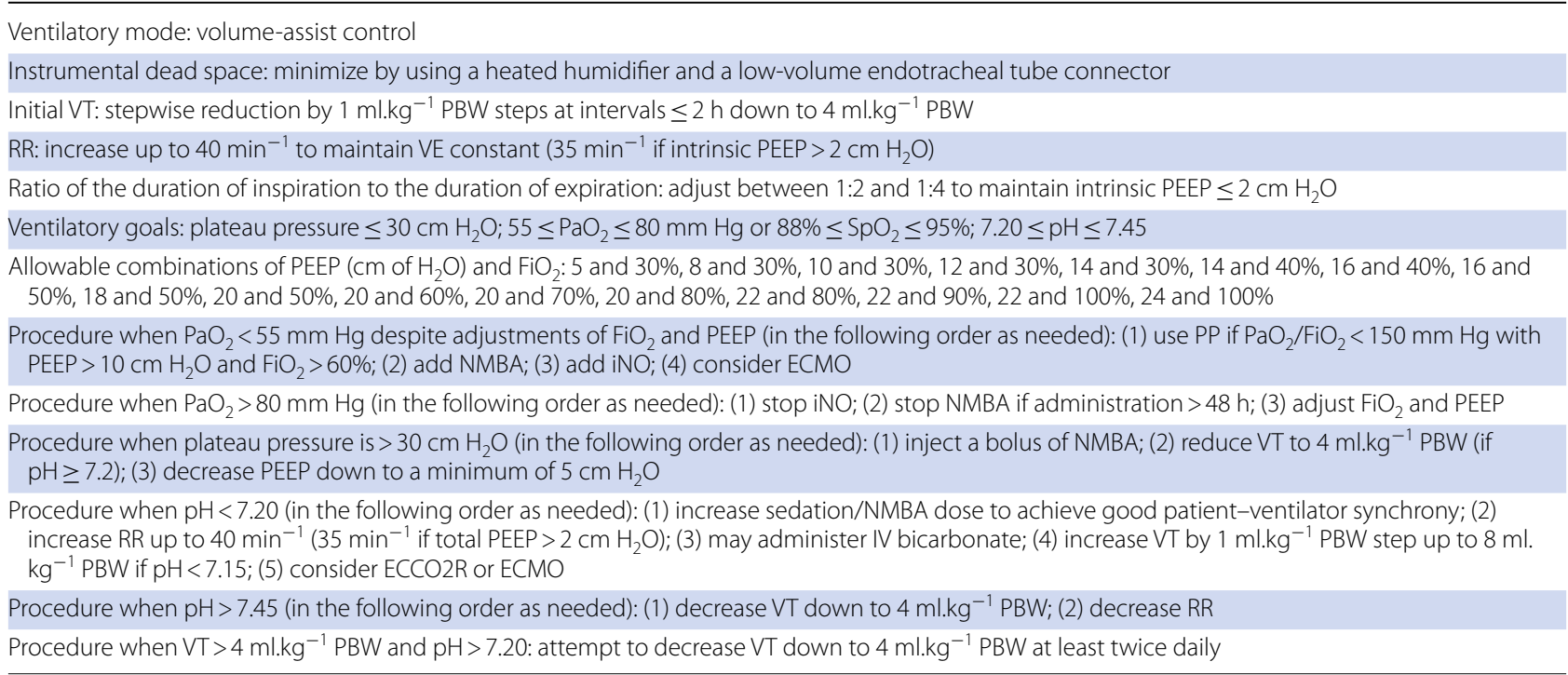

ECCO2R extracorporeal $\mathrm{CO}_{2}$ removal, ECMO extracorporeal membrane oxygenation, $\mathrm{FiO}_{2}$ fraction of inspired oxygen, $i N O$ inhaled nitric oxide, $N M B A$ neuromuscular blocking agent, $P a O_{2}$ partial pressure of arterial oxygen, $P B W$ predicted body weight, $P E E P$ positive end-expiratory pressure, $P P$ prone positioning, $R R$ respiratory rate, $\mathrm{SPO}_{2}$ oxyhemoglobin saturation measured by pulse oximetry, $V E$ minute-ventilation, $V T$ tidal volume

positioning, -3 to -2 until successful PEEP weaning trial, and -2 to 0 until successful spontaneous breathing trial.

\section{Data collection}

The following variables were recorded at inclusion: demographic and anthropometric data, time of ARDS identification, admission category, immunodeficiency, Mac Cabe and SAPS 2 scores, and ARDS risk factors. Ventilatory settings, RASS score, arterial blood gas and body position were recorded at $\mathrm{H}_{0}, \mathrm{H}_{2}-\mathrm{H}_{6}, \mathrm{H}_{8}-\mathrm{H}_{12}$, $\mathrm{H}_{16}-\mathrm{H}_{18}$, and daily until day 8 of the study in mechanically ventilated patients. Body weight, hemodynamic variables, vasopressor and sedation doses, SOFA score, and ARDS adjunctive therapies were recorded at inclusion, and daily until day 8 in mechanically ventilated patients. Septal kinetic, end-diastolic right and left ventricle areas were assessed by echocardiography at inclusion, and on day 2 and 3. Missing data are reported in Online Resource 3.

\section{Measurements}

Total PEEP (PEEP $\left.{ }_{\text {tot }}\right)$, intrinsic PEEP (PEEPi), and $P_{\text {Plat }}$ were measured after 3-s end-expiratory, and end-inspiratory occlusions. $\Delta P$ was computed as $P_{\text {Plat }}$ minus $P E E P_{\text {tot }}$. Mechanical power (MP) was computed as previously described [17], and partitioned into 3 components:

$$
\mathrm{VT}-\text { related } \mathrm{MP}=0.0098 \times \mathrm{RR} \times \mathrm{VT}^{2} \times \frac{1}{2} E l_{\mathrm{rs}},
$$

$$
\begin{aligned}
& \text { PEEP }- \text { related } \mathrm{MP}=0.0098 \times \mathrm{RR} \times \mathrm{VT} \times \mathrm{PEEP}_{\text {tot }}, \\
& \text { Resistive } \mathrm{MP}=0.0098 \times \mathrm{RR}^{2} \times \mathrm{VT}^{2} \times \frac{(1+I: E)}{60 \times I: E} R_{\mathrm{aw}},
\end{aligned}
$$

with $\mathrm{RR}=$ respiratory rate, $\mathrm{El}_{\mathrm{rs}}=$ elastance of the respiratory system, $I: E=$ inspiratory-to-expiratory ratio, and $R_{\mathrm{aw}}=$ airway resistance.

Acute cor pulmonale (ACP) was defined by the association of septal dyskinesia and end-diastolic right ventricle area/end-diastolic left ventricle area $>0.6$.

\section{Follow-up and endpoints}

Follow-up was performed for 90 days following inclusion. The primary endpoint was change in $\Delta P$ between day 2 of the study and inclusion. Secondary endpoints were: (1) rate of patients who achieved VT $\leq 4.2 \mathrm{ml} . \mathrm{kg}^{-1}$ (i.e., $4+5 \%$ to account for measurement error) during the first 2 days; (2) change in respiratory parameters, vasopressor and sedation dose during the first 2 days; (3) safety endpoints: change in end-diastolic right ventricle/left ventricle area during the first 2 days, rate of ACP, pneumothorax and any adverse event by category during the study; (4) 90-day mortality.

Successful PEEP weaning was defined as survival with PEEP $\leq 5 \mathrm{cmH}_{2} \mathrm{O}$ for $>48 \mathrm{~h}$ before day 28. Successful sedation weaning was defined as survival with sedation withdrawal for $>48 \mathrm{~h}$ before day 28. Successful extubation was defined as survival without the need for invasive 
MV for $>2$ days before day 28. VFD were computed as the number of days between weaning from invasive $\mathrm{MV}$ and day 28. Patients who died before weaning were considered to have 0 VFD. Severe acidosis was defined by a $\mathrm{pH}<7.15$.

\section{Statistical analysis}

We computed that with a sample of at least 33 patients, the study would have an $80 \%$ power to detect an absolute $\Delta P$ reduction of $3.5 \mathrm{cmH}_{2} \mathrm{O}$ between $\mathrm{H}_{0}$ and day 2 , using a two-sided test with a 0.05 type I error, assuming a standard deviation of $\Delta P$ at inclusion of $7 \mathrm{cmH}_{2} \mathrm{O}$ [6]. This value of $\Delta P$ was chosen as clinically relevant since it was associated with a relative risk reduction in mortality of 1.20 [6]. We decided conservatively to include 35 patients.

Numerical variables are expressed as median [1st quartile-3rd quartile], and categorical variables as counts (percentages). 95\% confidence intervals $\left(\mathrm{CI}_{95 \%}\right)$ for proportions were calculated using Wilson score test. The bias-corrected and accelerated bootstrap method was used to compute $\mathrm{CI}_{95 \%}$ for median [18]. Quantitative variables repeatedly measured over time were fitted with a linear mixed model using time as a categorial variable with fixed effect, and patient as variable with random effect. The impact of body position was tested by adding an interaction term in the models. Multiple comparisons between time points and $\mathrm{H}_{0}$ were performed using Dunnett's test. Binary variables were fitted with a logistic regression model, and independent variables with a $\mathrm{p}$ value below 0.2 in the univariate analyses were considered for inclusion in a multivariable logistic regression model, using backward stepwise descending selection. $\mathrm{CI}_{95 \%}$ for area under curve (AUC) were computed using the DeLong method. The optimal cut-off points were computed by maximizing the Youden index.

Statistical analysis was performed using $R$ (version 3.5.1) with packages PropCIs [19], lme4 [20], lmerTest [21], multcomp [22], pROC [23], OptimalCutpoints [24], and boot $[25,26]$. A $p$ value below 0.05 was chosen for statistical significance.

\section{Results}

\section{Characteristics at inclusion}

35 patients were included and the centers enrolled a median of 3 [1-4] patients. One patient's next of kin withdrew consent leaving 34 analyzable patients. Patients' characteristics at inclusion are reported in Table 2. 6 patients $(18 \%)$ presented with a $\mathrm{pH} \leq 7.20$ at inclusion.

\section{Physiological variables}

Changes in ventilatory parameters, arterial blood gas and SOFA sub-scores over the first 4 days are presented in
Table 2 Characteristics at inclusion

\begin{tabular}{|c|c|}
\hline Variables & Median [IQR] or count (\%) \\
\hline Age (year) & $67[53-73]$ \\
\hline Male gender & $25(74 \%)$ \\
\hline \multicolumn{2}{|l|}{ Admission category } \\
\hline Medical & $32(94 \%)$ \\
\hline Urgent surgery & $2(6 \%)$ \\
\hline SAPS 2 at ICU admission & $50[35-58]$ \\
\hline \multicolumn{2}{|l|}{ Mac Cabe score } \\
\hline No disease or non-fatal disease & $31(91 \%)$ \\
\hline Ultimately fatal disease & $2(6 \%)$ \\
\hline Rapidly fatal disease & $1(3 \%)$ \\
\hline Immunosuppression & $6(18 \%)$ \\
\hline \multicolumn{2}{|l|}{ ARDS risk factor } \\
\hline Pneumonia & $29(85 \%)$ \\
\hline Aspiration & $5(15 \%)$ \\
\hline Non-pulmonary sepsis & $3(9 \%)$ \\
\hline Other & $2(6 \%)$ \\
\hline \multicolumn{2}{|l|}{ ARDS severity at inclusion } \\
\hline Moderate & $17(50 \%)$ \\
\hline Severe & $17(50 \%)$ \\
\hline Time from ARDS identification (h) & $9[4-15]$ \\
\hline Tidal volume (ml.kg ${ }^{-1}$ PBW) & $6.0[5.9-6.1]$ \\
\hline Respiratory rate $\left(\mathrm{min}^{-1}\right)$ & $28[23-30]$ \\
\hline PEEP $\left(\mathrm{cm} \mathrm{H}_{2} \mathrm{O}\right)$ & $10[8-12]$ \\
\hline PEEPi $\left(\mathrm{cm} \mathrm{H}_{2} \mathrm{O}\right)$ & $1[0-1]$ \\
\hline Plateau pressure $\left(\mathrm{cm} \mathrm{H}_{2} \mathrm{O}\right)$ & 23 [19-27] \\
\hline Driving pressure $\left(\mathrm{cm} \mathrm{H}_{2} \mathrm{O}\right)$ & 12 [9-15] \\
\hline $\mathrm{PaO}_{2} / \mathrm{FiO}_{2}(\mathrm{~mm} \mathrm{Hg})$ & $101[78-132]$ \\
\hline $\mathrm{PaCO}_{2}(\mathrm{~mm} \mathrm{Hg})$ & $46[40-52]$ \\
\hline $\mathrm{pH}$ & $7.34[7.26-7.39]$ \\
\hline Bicarbonate (mmol. $\left.\mathrm{L}^{-1}\right)$ & $23[21-27]$ \\
\hline Base excess $\left(\mathrm{mmol}^{-\mathrm{L}^{-1}}\right)$ & $-1.8[-5.7$ to 1.8$]$ \\
\hline Vasopressor dose $\left(\mu \mathrm{g} \cdot \mathrm{kg}^{-1} \cdot \mathrm{min}^{-1}\right)$ & $0.23[0.04-0.56]$ \\
\hline Vasopressor administration (\%) & $27(79 \%)$ \\
\hline Arterial lactate $\left(\mathrm{mmol} . \mathrm{L}^{-1}\right)$ & $1.9[1.3-2.8]$ \\
\hline $\begin{array}{l}\text { Cumulative fluid balance since admission } \\
(\mathrm{kg})\end{array}$ & $0[0-1]$ \\
\hline SOFA score & $13[11-14]$ \\
\hline Acute cor pulmonale & $2(6 \%)$ \\
\hline $\begin{array}{l}\text { Neuromuscular blocking agent administra- } \\
\text { tion }\end{array}$ & $31(91 \%)$ \\
\hline Inhaled nitric oxide & $1(3 \%)$ \\
\hline Prone position & $7(21 \%)$ \\
\hline Renal replacement therapy & $4(12 \%)$ \\
\hline
\end{tabular}

$\mathrm{FiO}_{2}$ fraction of inspired oxygen, $I C U$ intensive care unit, IQR interquartile range, $\mathrm{PaCO}_{2}$ arterial partial pressure of carbon dioxide, $\mathrm{PaO}_{2}$ arterial partial pressure of oxygen, PEEP positive end-expiratory pressure, PEEPi intrinsic PEEP, SAPS 2 simplified acute physiology score, SOFA Sequential Organ Failure Assessment score 

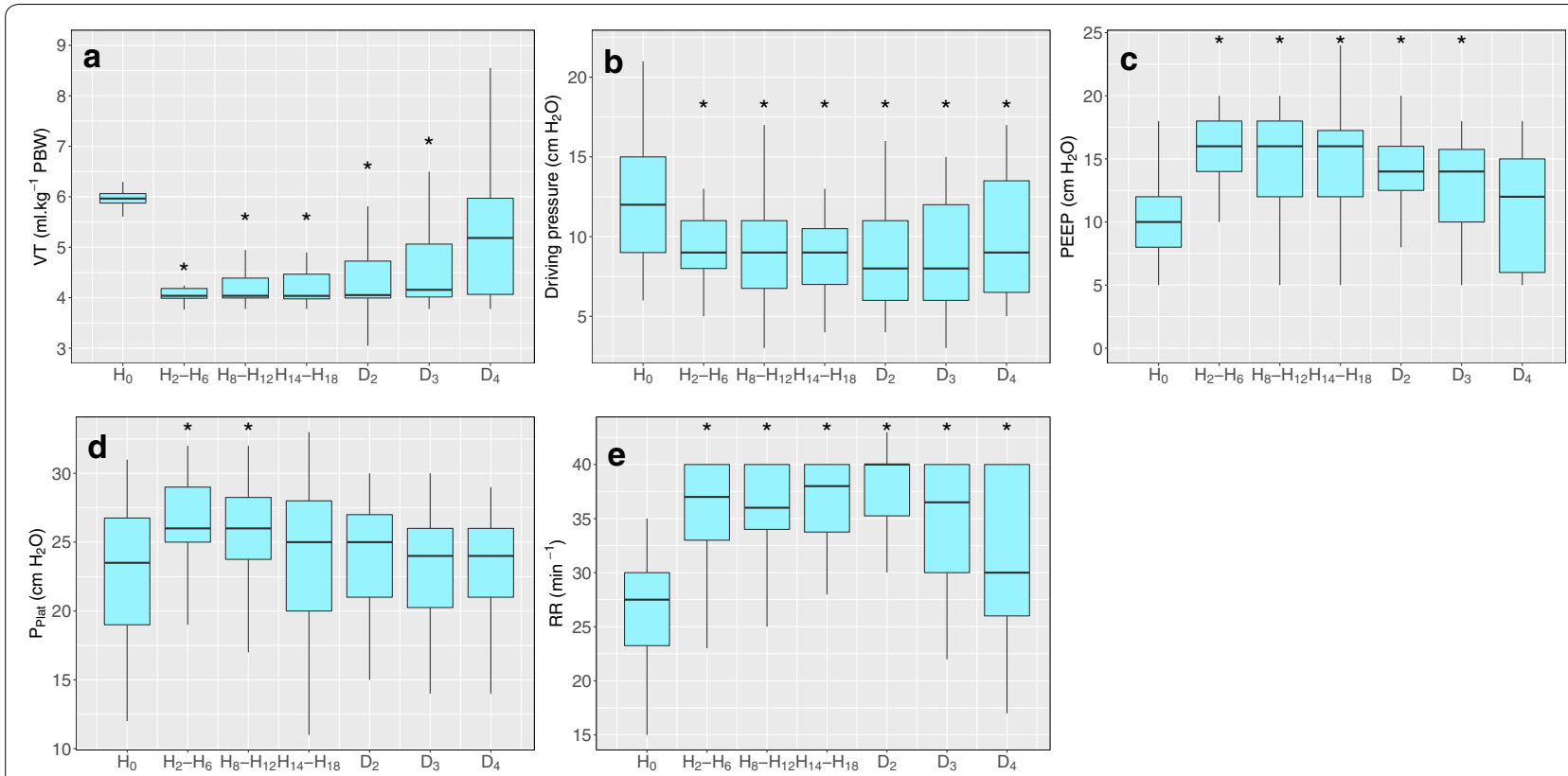

Fig. 1 Ventilatory parameters over the first 4 days following inclusion. ${ }^{*} p<0.05$ vs. $\mathrm{H}_{0} . \mathrm{H}_{0}, \mathrm{H}_{2}-\mathrm{H}_{6}, \mathrm{H}_{8}-\mathrm{H}_{12}, \mathrm{H}_{14}-\mathrm{H}_{18}=$ time intervals in hours following inclusion (day 1); $D_{2}, D_{3}, D_{4}=$ study day $2-4 ; P B W$ predicted body weight, $P E E P$ positive end-expiratory pressure, $P_{\text {Plat }}$ plateau pressure, $R R$ respiratory rate, $V T$ tidal volume
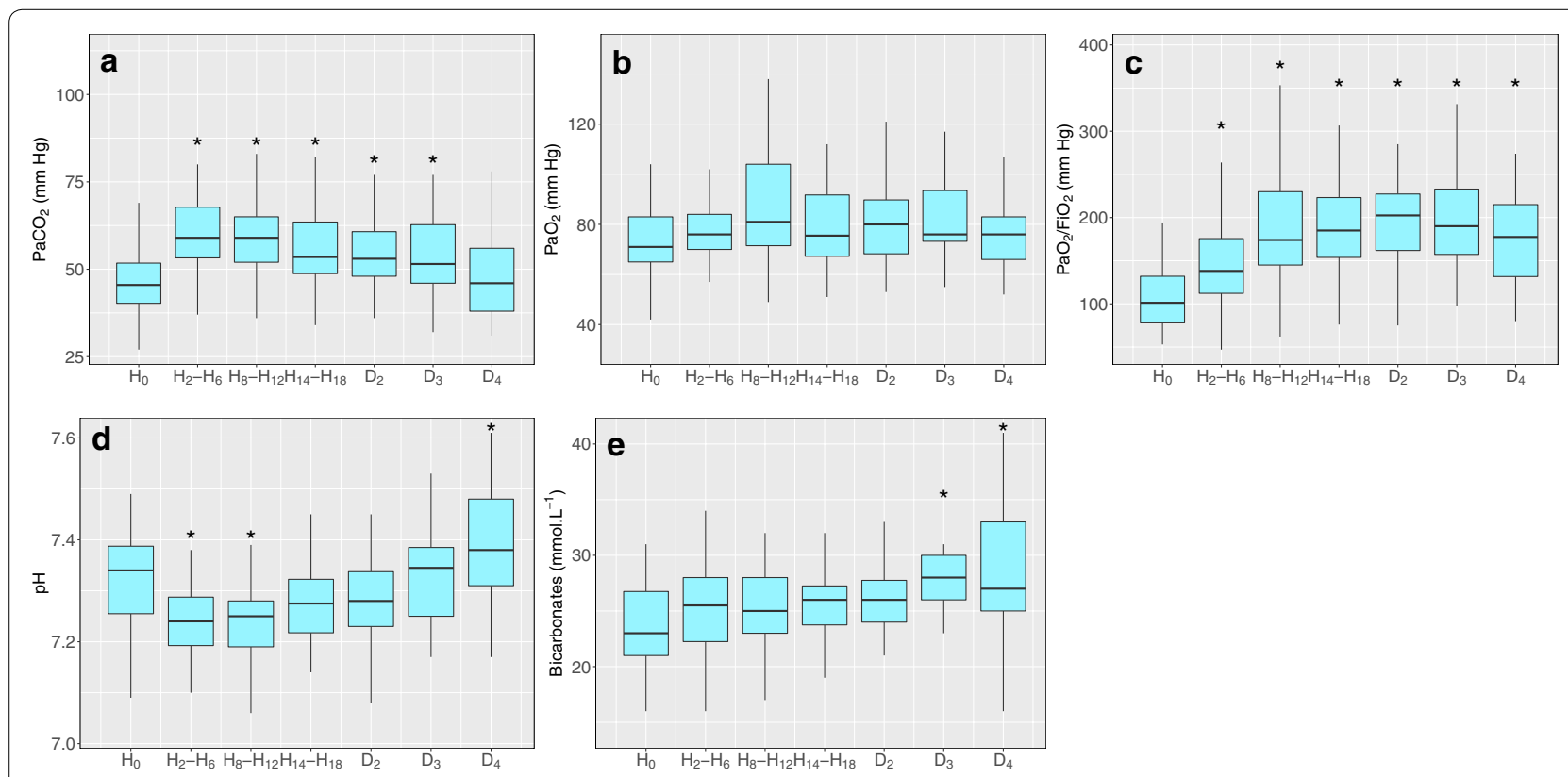

Fig. 2 Arterial blood gas over the first 4 days following inclusion. ${ }^{*} p<0.05$ vs. $\mathrm{H}_{0} . \mathrm{H}_{0}, \mathrm{H}_{2}-\mathrm{H}_{6}, \mathrm{H}_{8}-\mathrm{H}_{12}, \mathrm{H}_{14}-\mathrm{H}_{18}=$ time intervals in hours following inclusion (day 1); $\mathrm{D}_{2}, \mathrm{D}_{3}, \mathrm{D}_{4}$ study day 2-4, $\mathrm{FiO}_{2}$ fraction of inspired oxygen, $\mathrm{PaCO}_{2}$ arterial partial pressure of carbon dioxide, $\mathrm{PaO}$ arterial partial pressure of oxygen

Figs. 1 and 2, and in Online Resource 4 and 5. Between baseline and $\mathrm{D}_{2}$, VT decreased significantly from 6.0 [5.9-6.1] to 4.1 [4.0-4.7] $\mathrm{ml} . \mathrm{kg}^{-1} \mathrm{PBW}$, and RR increased significantly from 28 [23-30] to $40[35-40] \mathrm{min}^{-1}$. PEEP was significantly increased from $\mathrm{H}_{2}$ to $\mathrm{H}_{6}$ to $\mathrm{D}_{3}$ as compared to baseline, while PEEPi was not significantly 
modified during the first 4 days. $\mathrm{PaO}_{2} / \mathrm{FiO}_{2}$ and $\mathrm{PaCO}_{2}$ increased significantly from baseline values as early as $\mathrm{H}_{2}-\mathrm{H}_{6}$ up to $\mathrm{D}_{3}$, while $\mathrm{pH}$ was significantly lower than baseline only at $\mathrm{H}_{2}-\mathrm{H}_{6}$ and $\mathrm{H}_{8}-\mathrm{H}_{12}$ (Fig. 2).

\section{ARDS adjunctive therapies}

Rate of use of ARDS adjunctive therapies over the first 4 days is reported in Online Resource 6. Sedation drugs were not significantly modified over the first 4 days following inclusion.

\section{Efficacy}

The median difference in $\Delta P$ between day 2 and $\mathrm{H}_{0}$ amounted to $-4 \mathrm{cmH}_{2} \mathrm{O}\left(\mathrm{CI}_{95 \%}:-7\right.$ to -3$)$. The interaction between body position (supine or prone) and time of measurement was not significantly associated with $\Delta P$, suggesting that body position had no detectable impact on $\Delta P$ measurements. On day 2 , VT was $\leq 4.2 \mathrm{ml}$. $\mathrm{kg}^{-1}$ in 22 patients $\left(65 \%\left[\mathrm{CI}_{95 \%} 48 \%-79 \%\right]\right)$ and on day $3 \mathrm{VT}$ was $\leq 4.2 \mathrm{ml.kg}{ }^{-1}$ in 16 patients $\left(52 \%\left[\mathrm{CI}_{95 \%}\right.\right.$ $36 \%-69 \%]$ ). VT was $\leq 5.25 \mathrm{ml} . \mathrm{kg}^{-1}$ (i.e., $5 \mathrm{ml} . \mathrm{kg}^{-1}+5 \%$ ) in 30 patients $\left(88 \%\right.$ [ $\left.\left.\mathrm{CI}_{95 \%} 73 \%-95 \%\right]\right)$ on day 2 , and $\mathrm{VT}$ was $\leq 5.25 \mathrm{ml} . \mathrm{kg}^{-1}$ in 24 patients $\left(77 \%\right.$ [CI $\left.\left.\mathrm{CI}_{95 \%} 63 \%-90 \%\right]\right)$ on day 3. Patients were ventilated with a VT $\leq 4.2 \mathrm{ml} . \mathrm{kg}^{-1}$ or $\leq 5.25 \mathrm{ml} . \mathrm{kg}^{-1}$ during median times amounting to 2 [0-2] and 2 [1-4] days, respectively. Four patients (18\%) with VT $\leq 4.2 \mathrm{ml} . \mathrm{kg}^{-1}$ on day 2 presented at least one episode of severe acidosis during the study, as compared to $7(58 \%)$ with $\mathrm{VT}>4.2 \mathrm{ml} . \mathrm{kg}^{-1}$ on day 2 . Multivariate analysis identified coagulation SOFA sub-score and $\mathrm{pH}$ at inclusion as variables independently associated with $\mathrm{VT} \leq 4.2 \mathrm{ml} . \mathrm{kg}^{-1} \mathrm{PBW}$ on day 2 (Online Resource 7). $\mathrm{pH}$ at inclusion predicted $\mathrm{VT} \leq 4.2 \mathrm{ml} . \mathrm{kg}^{-1} \mathrm{PBW}$ on day 2 with an AUC of $0.72\left[\mathrm{CI}_{95 \%} 0.52-0.92, p<0.05\right]$, with a sensitivity of $95 \%$ and a specificity of $42 \%$ at a threshold of 7.21 .

\section{Mechanical power}

Total MP was computed in 11 patients and was not significantly modified over the first 4 days of the study (Online Resource 8). VT-related MP significantly decreased after inclusion, while PEEP-related MP increased. Resistive MP significantly decreased as a consequence of $R_{\text {aw }}$ decrease at higher PEEP.

\section{Outcome (online resource 9)}

Duration of MV was 11 [8-20] days. Fourteen patients (41\%) died before day 90 with median delay between inclusion and death amounting to 16 [9-22] days, among which $6(43 \%)$ died from refractory shock (Online Resource 10).

\section{Safety markers}

Adverse events are reported in Table 3. Sixteen episodes of severe acidosis were reported in 11 patients (32\%) and were the only adverse event directly connected to the study by attending physicians. Renal SOFA sub-score, $\mathrm{pH}$, base excess and bicarbonate at inclusion were associated with the occurrence of at least one episode of severe acidosis (Online Resource 11). Multivariate analysis identified renal SOFA sub-score and $\mathrm{pH}$ at inclusion as variables independently associated to the occurrence of at least one episode of severe acidosis. In addition to the two patients with ACP at study inclusion, two additional patients (6\%) developed ACP after inclusion. Right ventricle/left ventricle ratio increased non-significantly from 0.50 [0.50-0.72] at $\mathrm{H}_{0}(n=29)$ to $0.66[0.60-0.76]$ on day $2(n=27)$ and $0.73[0.56-0.79]$ on day $3(n=14)$.

\section{Discussion}

The main findings of the study are the following: (1) VT may be reduced down to $4 \mathrm{ml} . \mathrm{kg}^{-1}$ in approximately $2 / 3$ of moderately severe-to-severe ARDS patients, and to $5 \mathrm{ml} . \mathrm{kg}^{-1}$ in approximately $90 \%$, without ECCO2R, while targeting arterial $\mathrm{pH}$ above 7.20; (2) this strategy is associated with a $4 \mathrm{cmH}_{2} \mathrm{O}$ median decrease in $\Delta P 24 \mathrm{~h}$ after inclusion, at the price of substantial increase in $R R$ and transient episodes of severe acidosis in approximately $1 / 3$ of the patients; 3 -selecting patients with $\mathrm{pH}>7.20$ may increase the rate of patients in which ULTV is achievable.

\section{Efficacy}

While several studies including one RCT combining ULTV and ECCO2R have been performed [10-12, 27, 28 , the present study is the first prospective study testing the safety and feasibility of this strategy applied from the early phase of ARDS until oxygenation improvement without extracorporeal devices. Compared to the largest observational study on ECCO2R during ARDS [12], patients were more severely hypoxemic in the present study $\left(\mathrm{PaO}_{2} / \mathrm{FiO}_{2}=101 \mathrm{mmHg}\right.$ vs. $\left.173 \mathrm{mmHg}\right)$, had higher SOFA score (13 vs. 7$)$, and similar $\Delta P$ (12 vs. $13 \mathrm{cmH}_{2} \mathrm{O}$ ). Interestingly, the rate of patients achieving ULTV on day 2 was only slightly lower in the present study (65\%) than in Combes et al. study (82\%), with similar magnitude in $\Delta P$ reduction between inclusion and day 2. As expected, $\mathrm{PaCO}_{2}$ was substantially higher on day 2 in the present study (53 vs $46 \mathrm{mmHg}$ ).

However, whether the low VT strategy tested in the present study is truly ultraprotective is questionable, since 1-RR (a minor component of MP relative to $\Delta P$ [29]) had to be increased up to $40 \mathrm{~min}^{-1}$ in order to maintain $\mathrm{pH}$ in an acceptable range, and 2-total MP was unchanged after inclusion. However, recent experimental 
Table 3 Adverse events after inclusion

\begin{tabular}{|c|c|c|c|}
\hline Adverse events & Number of episodes & Number of patients (\%) & $\begin{array}{l}\text { Delay } \\
\text { of occur- } \\
\text { rence (day) }\end{array}$ \\
\hline \multicolumn{4}{|l|}{ Metabolic events } \\
\hline Severe mixed acidosis with $\mathrm{pH}<7.15$ & 16 & $11(32 \%)$ & $0[0-1]$ \\
\hline Other metabolic events & 1 & $1(3 \%)$ & $0[0-0]$ \\
\hline \multicolumn{4}{|l|}{ Respiratory events } \\
\hline Pneumothorax & 2 & $2(6 \%)$ & $6[4-7]$ \\
\hline Refractory hypoxemia requiring ECMO & 1 & $1(3 \%)$ & $1[1-1]$ \\
\hline Other & 6 & $6(18 \%)$ & $6[3-14]$ \\
\hline \multicolumn{4}{|l|}{ Infectious events } \\
\hline Nosocomial pneumonia & 14 & $13(38 \%)$ & $8[6-14]$ \\
\hline Non-respiratory infection site & 4 & $3(9 \%)$ & $9[8-11]$ \\
\hline Bacteremia & 8 & $7(21 \%)$ & $4[2-6]$ \\
\hline \multicolumn{4}{|l|}{ Cardiovascular events } \\
\hline Shock & 5 & $5(15 \%)$ & $13[6-15]$ \\
\hline Cardiac arrest & 3 & $3(9 \%)$ & $13[7-17]$ \\
\hline Acute cor pulmonale & 2 & $2(6 \%)$ & $1[1-1]$ \\
\hline Supraventricular tachycardia & 3 & $2(6 \%)$ & $1[1-6]$ \\
\hline \multicolumn{4}{|l|}{ Neurological events } \\
\hline ICU-acquired weakness & 5 & $5(15 \%)$ & $11[9-16]$ \\
\hline Central nervous system disease & 5 & $5(15 \%)$ & $7[6-11]$ \\
\hline Acute kidney injury & 8 & $8(24 \%)$ & $3[2-8]$ \\
\hline Digestive events & 5 & $4(12 \%)$ & $10[7-13]$ \\
\hline Acute liver failure & 3 & $3(9 \%)$ & $5[3-7]$ \\
\hline Multi-organ failure & 2 & $2(6 \%)$ & 14 [12-15] \\
\hline Hemorrhage & 3 & $3(9 \%)$ & 15 [14-15] \\
\hline
\end{tabular}

Values are number of episodes, number of patients with corresponding percentage, or median [1st quartile, 3rd quartile]

ECMO extracorporeal membrane oxygenation, ICU intensive care unit

studies have shown a beneficial effect of lowering VT while keeping total MP constant [30,31]. Furthermore, both resistive and VT-related MP significantly decreased after inclusion, but this was counterbalanced by a significant increase in PEEP-related MP, whose contribution to ventilator-induced lung injury (VILI) has been questioned [32], as there is no mechanical movement at a given PEEP level. Finally, RR is indeed associated with ARDS mortality [33], but may only reflect the clinician's attempt to normalize $\mathrm{PaCO}_{2}$ in the most severe patients.

Assuming $\Delta P$ is a surrogate of dynamic strain [6], the $33 \%$ decrease of this parameter combined with a $32 \%$ decrease in inspiratory time between $\mathrm{H}_{0}$ and day 2 in the present study, suggests that the current strategy would significantly decrease dynamic strain without significantly modifying strain rate (i.e., the ratio of strain over inspiratory time), another important determinant of VILI [34]. However, it is still unknown whether reducing VT below $6 \mathrm{ml} . \mathrm{kg}^{-1}$ is beneficial in unselected ARDS patients. A post hoc analysis of a RCT on ULTV combined with ECCO2R [11] identified a beneficial effect of this strategy on VFD in the subgroup of patients with $\mathrm{PaO}_{2} / \mathrm{FiO}_{2} \leq 150 \mathrm{mmHg}$ (i.e., the population selected in the present study). Selecting patients with high $\Delta P$ seems appealing, but the lack of indisputable safety value regarding this parameter [6-8], and the confounding influence of chest wall elastance questions the reliability of such strategy. Finally, the high PEEP strategy used in the present study [35] may have increased static strain, whose contribution to VILI is minimal relative to dynamic strain [36].

\section{Safety}

The main safety concern regarding the tested strategy is uncontrolled hypercapnia leading to severe acidosis in patients with acute kidney injury and low $\mathrm{pH}$. The concept of permissive hypercapnia was coined after 2 seminal studies [37, 38] performed in the early 1990s. In these non-controlled studies, ARDS patients were managed targeting a peak inspiratory pressure $<30 \mathrm{cmH}_{2} \mathrm{O}$, using low RR, and allowing the $\mathrm{PaCO}_{2}$ to increase to values similar to our study, and hospital mortality rates 
were below $30 \%$ (a value strikingly low for the era). While hypercapnia may have beneficial effects (such as inhibition of proinflammatory cytokines synthesis or attenuation of inflammation related to VILI), it was also shown to be deleterious on other physiological processes (such as inhibition of lung epithelial cell repair, inhibition of myogenic tone or increase of renal vascular resistance, among others) [39]. Hence, the net impact of severe hypercapnia remains to date unclear. Moreover, although hypercapnia $\geq 48 \mathrm{mmHg}$ is an independent risk factor for ACP, the rate of ACP was lower in the present study $(12 \%)$ than in the largest observational study in ARDS (22\%) [40], in line with the protective effect of $\Delta P$ reduction on ACP occurrence. However, we acknowledge that the high rate of missing echocardiographic values in the present study may have led to an underestimation of the ACP rate.

Finally, in the present study, 90-day mortality was similar to hospital mortality observed in the latest observational study on ECCO2R (38\%), despite greater severity of illness, suggesting that both strategies are credible candidates to be tested in future RCTs on ARDS.

\section{Strengths and limits}

Some limitations of the present study should be acknowledged. First, the non-controlled design precludes accounting for the effect of time on $\Delta P$ and other variables. Second, the ratio of screened to enrolled patients is unknown, as no screening log was recorded. Third, 5 patients who did not experienced severe acidosis did not achieve ultra-low VT settings on day 2, an indirect evidence of protocol violation suggesting that some investigators may not have been at ease with severe levels of hypercapnia. Fourth, the study does not provide any evidence regarding efficacy of ULTV on ARDS outcome.

Nevertheless, the present study demonstrates the feasibility of ULTV without ECCO2R, with a multicenter design including both academic and non-academic ICUs. Furthermore, it provides estimates of the effect of lowering VT on $\Delta P$ and of the adverse events rate, while identifying ARDS patients with $\mathrm{pH}>7.20$ as credible candidates for future RCTs.

Finally, it should be stressed that this study is a hypothesis-generating pilot study, and that $\Delta P$ reduction was achieved at the price of severe acidosis in one-third of patients, uncontrolled hypercapnia, and increased RR, whose effects on ARDS morbidity and mortality may outweigh the benefits of a potential reduction in VT-related VILI.

\section{Conclusion}

ULTV may be applied in approximately $2 / 3$ of moderately severe-to-severe ARDS patients without ECCO2R, with a $4 \mathrm{cmH}_{2} \mathrm{O}$ median reduction in $\Delta P$, at the price of transient episodes of severe acidosis in approximately $1 / 3$ of the patients.

\section{Electronic supplementary material}

The online version of this article (https://doi.org/10.1007/s00134-019-05776-x) contains supplementary material, which is available to authorized users.

\begin{abstract}
Author details
${ }^{1}$ Service de Médecine Intensive Réanimation, Hôpital De La Croix Rousse, Hospices Civils de Lyon, 103 Grande Rue de la Croix Rousse, 69004 Lyon, France. ${ }^{2}$ Université de Lyon, Université LYON I, Lyon, France. ${ }^{3}$ CREATIS INSERM 1044 CNRS 5220, Villeurbanne, France. ${ }^{4}$ Service de Réanimation Polyvalente, Centre Hospitalier Sud-Francilien, Corbeil-Essonnes, France. ${ }^{5}$ Service de Réanimation Médico-Chirurgicale, Hôpital André Mignaud, Le Chesnay, France. ${ }^{6}$ Service de Réanimation, Centre Hospitalier Annecy Genevois, Pringy, France. ${ }^{7}$ Service de Réanimation Médicale, CHU de la Cavale Blanche, Brest, France. ${ }^{8}$ Medical Intensive Care Department, University Hospital Centre Rouen, Rouen, France. ${ }^{9}$ Inserm U 1096, Institute for Research and Innovation in Biomedicine (IRIB), Rouen University, Rouen, France. ${ }^{10}$ Service de Réanimation Médicale, Hôpital François Mitterrand, Dijon, France. ${ }^{11}$ Service de Réanimation Médicale, Hôpital Archet 1, Nice, France. ${ }^{12}$ Service de Réanimation, Centre Hospitalier Lyon Sud, Pierre-Bénite, France. ${ }^{13}$ Service de Réanimation Médicale Polyvalente, CHU Gabriel-Montpied, Clermont-Ferrand, France. ${ }^{14}$ Service de Réanimation Polyvalente, Centre Hospitalier de Beauvais, Beauvais, France.
\end{abstract}

\section{Acknowledgements}

The authors wish to thank Loredana Baboi for her help with data analysis. List of collaborators: Pascal Andreu (Dijon), Laetitia Bodenes (Brest), Sébastien Cavelot (Versailles), Nader Chebib (Lyon), Auguste Dargent (Dijon), Nicolas Ferriere (Brest), Gurvan Le Bouar (Rouen), Stéphane Legriel (Versailles), Romain Mercier (Beauvais), Mehdi Mezidi (Lyon), Nathalie Verrier (Beauvais).

Compliance with ethical standards

\section{Conflicts of interest}

On behalf of all authors, the corresponding author states that there is no conflict of interest.

\section{Statement of human rights}

The authors state that the study has been approved by a national research ethics committee (Comité de Protection des Personnes Sud-Est IV-RCB 2016 A00503-48) and has been performed in accordance with the ethical standards as laid down in the 1964 Declaration of Helsinki and its later amendments or comparable ethical standards.

Statement on the welfare of animal

This article does not contain any studies with animals performed by any of the authors.

Informed consent

Informed consent was obtained from all individual participants included in the study.

\section{Publisher's Note}

Springer Nature remains neutral with regard to jurisdictional claims in published maps and institutional affiliations.

Received: 20 May 2019 Accepted: 3 September 2019

Published online: 23 September 2019

\section{References}

1. Bellani G, Laffey JG, Pham T et al (2016) Epidemiology, patterns of care, and mortality for patients with acute respiratory distress syndrome in intensive care units in 50 countries. JAMA 315:788-800. https://doi. org/10.1001/jama.2016.0291 
2. Guerin C, Reignier J, Richard J-C et al (2013) Prone positioning in severe acute respiratory distress syndrome. N Engl J Med 368:2159-2168. https ://doi.org/10.1056/NEJMoa1214103

3. Cavalcanti AB, Suzumura ÉA, Writing Group for the Alveolar Recruitment for Acute Respiratory Distress Syndrome Trial (ART) Investigators et al (2017) Effect of Lung Recruitment and Titrated Positive End-Expiratory Pressure (PEEP) vs Low PEEP on Mortality in Patients With Acute Respiratory Distress Syndrome: A Randomized Clinical Trial. JAMA 318:13351345. https://doi.org/10.1001/jama.2017.14171

4. Beitler JR, Sarge T, Banner-Goodspeed VM et al (2019) Effect of titrating positive end-expiratory pressure (PEEP) with an esophageal pressureguided strategy vs an empirical high PEEP-Fio2 strategy on death and days free from mechanical ventilation among patients with acute respiratory distress syndrome: a randomized clinical trial. JAMA. https://doi. org/10.1001/jama.2019.0555

5. Terragni PP, Rosboch G, Tealdi A et al (2007) Tidal hyperinflation during low tidal volume ventilation in acute respiratory distress syndrome. Am J Respir Crit Care Med 175:160-166

6. Amato MBP, Meade MO, Slutsky AS et al (2015) Driving pressure and survival in the acute respiratory distress syndrome. N Engl J Med 372:747755. https://doi.org/10.1056/NEJMsa1410639

7. Sahetya SK, Mancebo J, Brower RG (2017) Fifty years of research in ards. vt selection in acute respiratory distress syndrome. Am J Respir Crit Care Med 196:1519-1525. https://doi.org/10.1164/rccm.201708-1629Cl

8. Villar J, Martín-Rodríguez C, Domínguez-Berrot AM et al (2017) A quantile analysis of plateau and driving pressures: effects on mortality in patients with acute respiratory distress syndrome receiving lung-protective ventilation. Crit Care Med 45:843-850. https://doi.org/10.1097/CCM.00000 00000002330

9. Needham DM, Yang T, Dinglas VD et al (2015) Timing of low tidal volume ventilation and intensive care unit mortality in acute respiratory distress syndrome. A prospective cohort study. Am J Respir Crit Care Med 191:177-185. https://doi.org/10.1164/rccm.201409-15980C

10. Terragni PP, Del Sorbo L, Mascia L et al (2009) Tidal volume lower than $6 \mathrm{ml} / \mathrm{kg}$ enhances lung protection: role of extracorporeal carbon dioxide removal. Anesthesiology 111:826-835. https://doi.org/10.1097/ ALN.0b013e3181b764d2

11. Bein T, Weber-Carstens S, Goldmann A et al (2013) Lower tidal volume strategy $\left(\approx 3 \mathrm{ml} / \mathrm{kg}\right.$ ) combined with extracorporeal $\mathrm{CO}_{2}$ removal versus "conventional" protective ventilation $(6 \mathrm{ml} / \mathrm{kg})$ in severe ARDS: the prospective randomized Xtravent-study. Intensive Care Med 39:847-856. https://doi.org/10.1007/s00134-012-2787-6

12. Combes A, Fanelli V, Pham T et al (2019) Feasibility and safety of extracorporeal $\mathrm{CO}_{2}$ removal to enhance protective ventilation in acute respiratory distress syndrome: the SUPERNOVA study. Intensive Care Med 45:592-600. https://doi.org/10.1007/s00134-019-05567-4

13. Acute Respiratory Distress Syndrome Network, Brower RG, Matthay MA et al (2000) Ventilation with lower tidal volumes as compared with traditional tidal volumes for acute lung injury and the acute respiratory distress syndrome. The acute respiratory distress syndrome network. N Engl J Med 342:1301-1308. https://doi.org/10.1056/NEJM20000504342 1801

14. Papazian L, Forel JM, Gacouin A et al (2010) Neuromuscular blockers in early acute respiratory distress syndrome. N Engl J Med 363:1107-1116. https://doi.org/10.1056/NEJMoa1005372

15. Definition Task Force ARDS, Ranieri VM, Rubenfeld GD et al (2012) Acute respiratory distress syndrome: the Berlin definition. JAMA 307:2526-2533. https://doi.org/10.1001/jama.2012.5669

16. Sessler CN, Gosnell MS, Grap MJ et al (2002) The Richmond agitationsedation scale: validity and reliability in adult intensive care unit patients. Am J Respir Crit Care Med 166:1338-1344. https://doi.org/10.1164/ rccm. 2107138

17. Gattinoni L, Tonetti T, Cressoni M et al (2016) Ventilator-related causes of lung injury: the mechanical power. Intensive Care Med 42:1567-1575. https://doi.org/10.1007/s00134-016-4505-2

18. Efron B (1987) Better bootstrap confidence intervals. J Am Stat Assoc 82:171-185

19. Scherer R (2018) PropCls: various confidence interval methods for proportions
20. Bates D, Maechler M, Bolker B, Walker S (2015) Fitting linear mixed-effects models using. J Stat Softw 67:1-48. https://doi.org/10.18637/jss.v067.i01

21. Kuznetsova A, Brockhoff PB, Christensen RHB (2017) ImerTest Package: Tests in Linear Mixed Effects Models. J Stat Softw 82:1-26. https://doi. org/10.18637/jss.v082.i13

22. Hothorn T, Bretz F, Westfall $P$ (2008) Simultaneous inference in general parametric models. Biom J 50:346-363. https://doi.org/10.1002/ bimj. 200810425

23. Robin X, Turck N, Hainard A et al (2011) pROC: an open-source package for R and S + to analyze and compare ROC curves. BMC Bioinform 12:77. https://doi.org/10.1186/1471-2105-12-77

24. Lopez-Raton M, Rodriguez-Alvarez MX, Cadarso-Suárez C, GudeSampedro F (2014) Optimal cutpoints: an R package for selecting optimal cutpoints in diagnostic tests. J Stat Softw 61:1-36

25. Canty A, Ripley B (2019) boot: Bootstrap R (S-Plus) functions. R package version $1.3-22$

26. Davidson AC, Hinkley DV (1997) bootstrap methods and their applications. Cambridge University Press, Cambridge

27. Schmidt M, Jaber S, Zogheib E et al (2018) Feasibility and safety of low-flow extracorporeal $\mathrm{CO}_{2}$ removal managed with a renal replacement platform to enhance lung-protective ventilation of patients with mild-to-moderate ARDS. Crit Care 22:122. https://doi.org/10.1186/s1305 4-018-2038-5

28. Fanelli V, Ranieri MV, Mancebo J et al (2016) Feasibility and safety of low-flow extracorporeal carbon dioxide removal to facilitate ultraprotective ventilation in patients with moderate acute respiratory distress syndrome. Crit Care 20:36. https://doi.org/10.1186/s13054-016-1211-y

29. Gattinoni L, Tonetti T, Cressoni M et al (2016) Ventilator-related causes of lung injury: the mechanical power. Intensive Care Med 42:1567-1575. https://doi.org/10.1007/s00134-016-4505-2

30. Santos RS, de Maia LA, Oliveira MV et al (2018) Biologic impact of mechanical power at high and low tidal volumes in experimental mild acute respiratory distress syndrome. Anesthesiology 128:1193-1206. https://doi.org/10.1097/ALN.00000000000002143

31. Moraes L, Silva PL, Thompson A et al (2018) Impact of different tidal volume levels at low mechanical power on ventilator-induced lung injury in rats. Front Physiol 9:318. https://doi.org/10.3389/fphys.2018.00318

32. Huhle R, Serpa Neto A, Schultz MJ, Gama de Abreu M (2018) Is mechanical power the final word on ventilator-induced lung injury? - no. Ann Transl Med 6:394. https://doi.org/10.21037/atm.2018.09.65

33. Laffey JG, Bellani G, Pham T et al (2016) Potentially modifiable factors contributing to outcome from acute respiratory distress syndrome: the LUNG SAFE study. Intensive Care Med 42:1865-1876. https://doi.org/10.1007/ s00134-016-4571-5

34. Protti A, Maraffi T, Milesi M et al (2016) Role of strain rate in the pathogenesis of ventilator-induced lung edema. Crit Care Med 44:e838-e845. https //doi.org/10.1097/CCM.0000000000001718

35. Richard JC, Maggiore SM, Jonson B et al (2001) Influence of tidal volume on alveolar recruitment. Respective role of PEEP and a recruitment maneuver. Am J Respir Crit Care Med 163:1609-1613

36. Protti A, Andreis DT, Monti M et al (2013) Lung stress and strain during mechanical ventilation: any difference between statics and dynamics? Crit Care Med 41:1046-1055. https://doi.org/10.1097/CCM.0b013e3182 $7417 a 6$

37. Hickling KG, Henderson SJ, Jackson R (1990) Low mortality associated with low volume pressure limited ventilation with permissive hypercapnia in severe adult respiratory distress syndrome. Intensive Care Med 16:372-377

38. Hickling KG, Walsh J, Henderson S, Jackson R (1994) Low mortality rate in adult respiratory distress syndrome using low-volume, pressure-limited ventilation with permissive hypercapnia: a prospective study. Crit Care Med 22:1568-1578

39. Barnes T, Zochios V, Parhar K (2018) Re-examining permissive hypercapnia in ARDS: a narrative review. Chest 154:185-195. https://doi.org/10.1016/j. chest.2017.11.010

40. Mekontso Dessap A, Boissier F, Charron C et al (2016) Acute cor pulmonale during protective ventilation for acute respiratory distress syndrome: prevalence, predictors, and clinical impact. Intensive Care Med 42:862-870. https://doi.org/10.1007/s00134-015-4141-2 